\title{
Selection of Invasive Wild Pig Countermeasures Using Multicriteria Decision Analysis
}

\author{
Matthew C. Brondum ${ }^{1}$, Zachary A. Collier ${ }^{1}$, Christopher S. Luke², Buddy L. Goatcher ${ }^{1}$ \\ ${ }^{1}$ US Army Engineer Research and Development Center, 3909 Halls Ferry Road, Vicksburg, MS, \\ 39180, USA, matthew.c.brondum@usace.army.mil, 601-634-3636 \\ ${ }^{2}$ Louisiana Tech University
}

\begin{abstract}
Wild pigs are a widespread invasive species that pose significant environmental and social risks. A number of wild pig eradication and control measures exist, but many eradication campaigns are ultimately unsuccessful. Decision making regarding how to design and execute an eradication plan is difficult because of multiple costs and benefits spanning various decision criteria that are associated with different eradication and control countermeasures. Moreover, multiple stakeholders are often involved with differing and sometimes competing objectives, and wild pigs are adaptive adversaries, meaning that the ideal countermeasure may change over time. In this paper, we propose the use of formal decision analytic tools which can structure decision problems into a set of relevant criteria, countermeasures, and stakeholder preferences to facilitate the evaluation of tradeoffs. We operationalize this method in a simple Excel-based decision tool and conclude with a path forward regarding how to successfully implement such tools for effective wild pig control.
\end{abstract}

Keywords: adaptive management, decision analysis, feral pig, integrated pest management, invasive species, nuisance species, Sus scrofa, wild pig 


\section{Introduction}

Wild pigs (Sus scrofa) are an invasive species sweeping across the nation causing massive amounts of damage, sometime irreparable, to both the environment and the economy. This nuisance species now resides in 39 US states and causes an estimated $\$ 1.5$ billion in economic damage each year (Pimental 2007; USDA 2014). Drastic expansion of wild pigs can be seen in the maps provided by the Southeastern Cooperative Wildlife Disease Study (2016) (Figure 1).
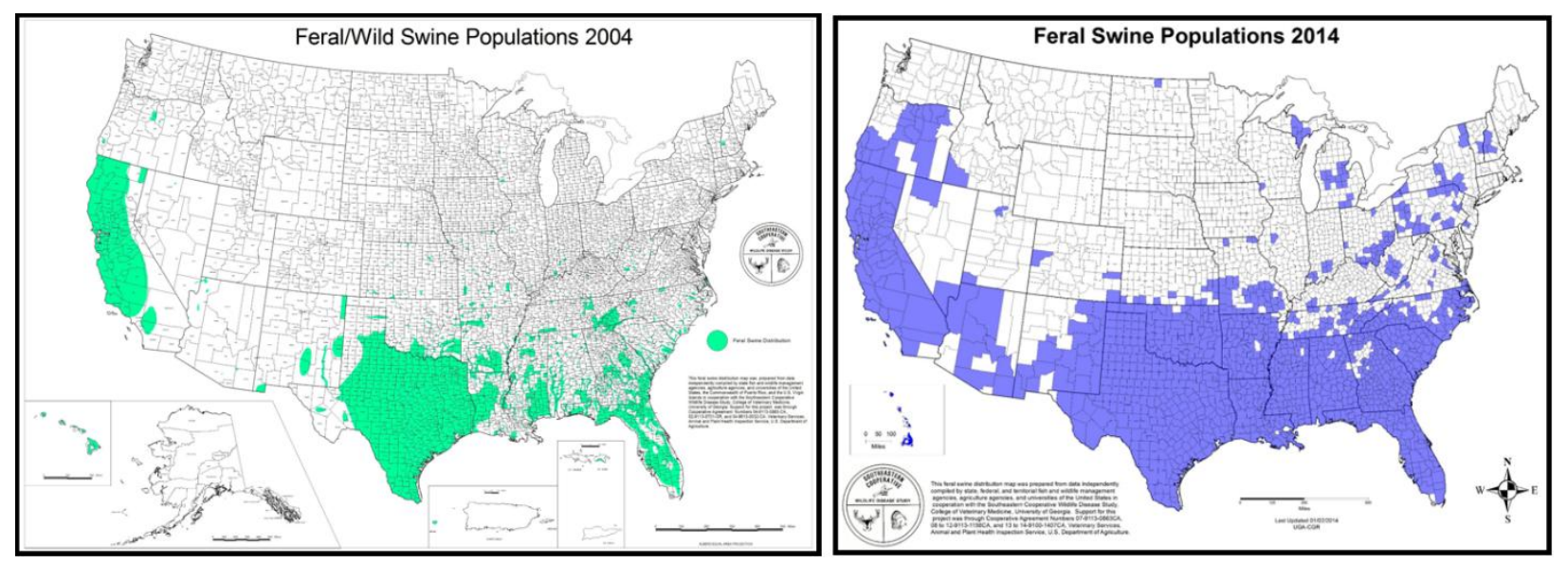

Figure 1. Wild pig expansion from 2004 to 2014

Engeman et al. (2003) estimated the damage caused by wild pigs at three state parks in Florida ranged from $\$ 5,331$ to $\$ 43,257$ per hectare. Wild pigs root up local flora and consume just about any fauna that comes across their paths including lambs, calves, fawns, crustaceans, fish, ground-nesting bird eggs, alligator eggs, and even the eggs of highly endangered sea turtles (Elsey et al. 2012; USDA 2013; USDA 2014). Other environmental consequences include disruption of natural food webs and degradation to terrestrial and aquatic habitats (Engeman et al., 2007a; Mersinger \& Silvy 2007; Kaller et al., 2007; Choquenot et al., 1996). Along with these damages, wild pigs can also serve as vectors for a number of diseases transmissible to animals and humans, including the spread of over 30 wildlife (sylvatic), human (zoonotic) and 
livestock diseases as well as 37 parasites (Wood and Barrett 1979; Forrester 1991; Davidson and Nettles 1997; Samuel et al. 2001; Williams and Barker 2001; Diaz 2007). Wild pigs are widely known to reduce water quality through wallowing as well as acting as a vector for the spread of parasites (Campbell \& Long, 2009). Furthermore, wild pigs also threaten the integrity of Native American and other significant cultural sites (Pfeiffer and Voeks 2008).

Executive Order 13112 (1999), "Invasive Species”, calls for federal agencies to “detect and respond rapidly to and control populations of such species in a cost-effective and environmentally sound manner", where the term "control" refers to "eradicating, suppressing, reducing, or managing invasive species populations, preventing spread of invasive species from areas where they are present, and taking steps such as restoration of native species and habitats to reduce the effects of invasive species and to prevent further invasions". Implicit in this definition is the need to assess different control countermeasures in a way that is both costeffective and environmentally sound. This paper seeks to address this issue by combining a traditional understanding of wild pigs with contextually relevant decision science methods.

In order to comply with the Executive Order, a number of eradication and control methods exist including trapping, snaring, ground shooting with or without the use of hunting dogs, aerial shooting, exclusion barriers and electronic tracking of a Judas pig (Zwickel 1971; Barret et al. 1988; Baubet et al. 2004; Wilcox et al. 2004; McCann and Garcelon 2008). However, while wildlife managers have many tools at their disposal, most, if not all, eradication campaigns are ultimately unsuccessful (Bomford and O’Brien 1995). Eradication campaigns in general are extremely challenging due to the ability for wild pigs to adapt as well as reproduce and spread so rapidly. Many of these failures stem from faulty decision making. Planning for eradication and control programs is conventionally an extremely difficult task where tradeoffs 
must be made under uncertainty about the efficacy of the various available countermeasures

(Maguire 2004). Managers in charge of an eradication or control project have to look at the "pros and cons" between the different countermeasures based on a number of different criteria such as cost, political sensitivity, technical feasibility, and impacts to non-target species and surrounding habitat. Table 1 illustrates some of the strengths and weaknesses associated with common eradication countermeasures. In addition to assessing these costs and benefits across alternative courses of actions, which may vary depending on case-specific factors, managers may also have to elicit and incorporate varying stakeholder interests. For instance, sport hunters may value wild pigs for recreational purposes, and native inhabitants in regions like the Deep South or Hawaii attach cultural significance to them (Izac and O'Brien 1989; Maguire 2004).

\begin{tabular}{|c|c|c|}
\hline Methods & Strengths & Weaknesses \\
\hline Fencing & $\begin{array}{l}\text { - Non-lethal way to protect property } \\
\text { - Covers large areas }\end{array}$ & $\begin{array}{l}\text { - Very expensive to build } \\
\text { - Very expensive and time consuming to } \\
\text { maintain } \\
\text { - Can cause swine to move and cause } \\
\text { damage to adjacent areas } \\
\end{array}$ \\
\hline $\begin{array}{l}\text { Cage/ Coral } \\
\text { Trapping }\end{array}$ & $\begin{array}{l}\text { - Multiple animals can be obtained } \\
\text { simultaneously } \\
\text { - Can be non-lethal } \\
\text { - Non-target animal may be released unharmed }\end{array}$ & $\begin{array}{l}\text { - Less effective if natural food is abundant } \\
\text { - Bait can become expensive } \\
\text { - Can take a long time }\end{array}$ \\
\hline Snaring & $\begin{array}{l}\text { - Least Expensive Technique } \\
\text { - Effective at low population densities } \\
\text { - May catch wary animal for which other } \\
\text { techniques fail }\end{array}$ & $\begin{array}{l}\text { - Non-target animals may be susceptible } \\
\text { - Only one animal can be obtained at once } \\
\text { - Cannot be used where snare anchor points } \\
\text { are limited } \\
\text { - Considered inhumane if not checked } \\
\text { regularly } \\
\text { - Can take large amounts of time }\end{array}$ \\
\hline $\begin{array}{l}\text { Ground } \\
\text { Shooting }\end{array}$ & $\begin{array}{l}\text { - May be conducted during night } \\
\text { - Highly selective } \\
\text { - May remove trap wary animals }\end{array}$ & $\begin{array}{l}\text { - Time and labor intensive } \\
\text { - Low success rates when population } \\
\text { densities are low } \\
\text { - May be limited by access }\end{array}$ \\
\hline Aerial Shooting & $\begin{array}{l}\text { - Highly selective in that only target animals are } \\
\text { removed } \\
\text { - Rapid removal of many animals } \\
\text { - Effective for removal of remnant animals } \\
\text { following other methods }\end{array}$ & $\begin{array}{l}\text { - Very Expensive } \\
\text { - Less effective with high land cover } \\
\text { - Can be hazardous, particularly In rugged } \\
\text { topography }\end{array}$ \\
\hline $\begin{array}{l}\text { Hunting with } \\
\text { dogs }\end{array}$ & $\begin{array}{l}\text { - Effective in targeting evasive animals } \\
\text { - Many animals removed in a short time } \\
\text { - Effective when population densities are high } \\
\text { - May provide public access to hunting resources }\end{array}$ & $\begin{array}{l}\text { - Dogs may be injured or killed when } \\
\text { baying large animals } \\
\text { - Dog training is very labor intensive } \\
\text { - Insufficiently Trained dogs may take non- }\end{array}$ \\
\hline
\end{tabular}




\begin{tabular}{|l|l|l|}
\hline & & $\begin{array}{l}\text { target animals } \\
\bullet\end{array}$ \\
& Expensive upkeep \\
\hline
\end{tabular}

Table 1. Comparison of eradication and control methods [adapted] (Campbell \& Long, 2009).

Additional definitions of methodologies are contained in Table 4.

Choosing the wrong eradication technique may cause a significant long-term detriment towards the affected region. When an eradication technique is used and fails, wild pigs are often intelligent enough to recognize similar situations and adapt to avoid them. This ultimately renders singular methods ineffective (Choquenot et al. 1999; Campbell and Long 2009) and making detection in low population densities problematic. Consequently, after an eradication countermeasure is selected and executed, managers are tasked with establishing a focused longterm monitoring and contingency plan that will aid in effectively managing this ever-evolving species (Engeman et al. 2007b; Ramsey et al. 2008). Invasive species managers unfortunately find themselves left to make these complex planning, execution, and monitoring decisions unaided. Given these tradeoffs and uncertainties in eradication and control programs, integrated methods are required to guide managers through the decision making process and provide insights into the relative merits and shortcomings of the different courses of action available. The field of Decision Analysis (Raiffa 1968; Howard 1988; Clemen 1996) offers a variety of methodological tools to aid in the decision making process. Decision Analysis is defined by Howard (2007) as "a logical procedure for the balancing of the factors that influence a decision. The procedure incorporates uncertainties, values, and preferences in a basic structure that models the decision." The field of multi-criteria decision analysis (MCDA) extends the principles of Decision Analysis to problems involving multiple, dissimilar, and difficult to quantify criteria (Belton \& Stewart 2002; Linkov and Moberg 2011). Belton and Stewart (2002) define MCDA as “... a collection of formal approaches which seek to take explicit account of multiple criteria in helping individuals or groups explore decisions that matter." MCDA 
methods generally involve the construction of a decision matrix for the structured analysis of alternatives across the relevant criteria and sub-criteria. The various methods differ in assessment and utilization of weights, their synthesis of information, and presentation of results (Yoe 2002; Løken 2007). Some common MCDA methods include Multi-Attribute Utility Theory (MAUT) (Keeney and Raiffa 1976), Analytic Hierarchy Process (AHP) (Saaty 1980), and outranking approaches (Kangas et al. 2001). A review of MCDA shows a steady increase in applications of this methodology in the environmental literature (Huang et al. 2011). In general, the MCDA methodology method follows a seven step process. These steps are outlined in Table 2 on the left-hand side. On the right-hand side of Table 2 is a brief description of how we applied this to invasive wild pigs.

\begin{tabular}{|l|l|}
\hline General MCDA Step & Application to Invasive Wild Pigs \\
\hline objective of the decision & $\begin{array}{l}\text { Wild pigs cause significant damage to Army lands } \\
\text { and are able to spread quickly and adapt incredibly } \\
\text { well to their surrounds. We seek to identify the } \\
\text { best eradication technique depending on site } \\
\text { specific conditions. }\end{array}$ \\
\hline (2) Identify evaluation criteria consistent & $\begin{array}{l}\text { Public Acceptance, Environmental Impact, Non- } \\
\text { target Species Impact, Total Cost, Training } \\
\text { (3) Identify alternatives (i.e., }\end{array}$ \\
\hline countermeasures) & $\begin{array}{l}\text { Needed, Efficacy, Land Traversing, } \\
\text { (4) Score alternatives based on their }\end{array}$ \\
\hline
\end{tabular}




\begin{tabular}{|l|l|}
\hline performance across the evaluation & context we use an expert opinion survey to \\
criteria & compute scores $\left(S_{i j}\right)$ for each countermeasure $(i)$ \\
and criterion $(j)$
\end{tabular}

\section{Table 2. Overview of Multi-Criteria Decision Analysis Steps}

Decision analytic tools have been applied to situations involving invasive species such as management of the European House Borer (Liu et al. 2010) and prioritizing the threats posed by invasive pests (Cook and Proctor 2007) and weed species (Benke et al. 2010). MCDA methods were used to determine optimal reintroduction efforts for whooping cranes (Converse et al. 2012), the protection of endangered salmon (Gregory and Long 2009), and selection of management options for feral cats (Lohr et al. 2014). Despite the relative success of using Decision Analytic tools to manage other invasive species and conservation issues, no applications have been documented for wild pigs. The closest example is found in Maguire (2004), where wild pigs in Hawaii were presented as a hypothetical example of how decision tools could be used to help in invasive species management. No subsequent publications 
document a follow-up to Maguire (2004) regarding applying decision analytic techniques towards managing wild pigs.

As the economic, environmental, and cultural damage caused by invasive wild pigs has dramatically increased in recent years (Pimental 2007; USDA 2014), the need for a change in how wildlife managers deal with these pigs has become more and more evident. In this article, we propose the use of a novel decision tool to aid in the analysis of tradeoffs between alternative courses of action, and based on monitoring data, adaptively select follow-up actions should wild pigs reappear at a site. Clemen and Reilly (1996) explain that decision analytic methodologies seek to not simply tell a decision maker what they should do, but rather it seeks to inform the user of the decision context, countermeasures, and values. By making these transparent, we enable the decision maker to consider a very logical approach which focuses on their values. It should be noted that the decision maker we focus on are natural resource managers, but could also include other affected stakeholders interested in removing wild pigs.

The remainder of this paper is laid out as follows. Section 2 focuses on describing the relevance and adaptation of MCDA decision methods to the context of wild pig countermeasure selection. Section 3 describes the development of expert opinion surveys which are used to score countermeasures based upon various criteria. Section 4 then discusses a notional but realistic case study of how this model could be applied in the real world to a farmer looking to eradicate pigs from his medium sized farmland. Lastly, Section 5 discusses the conclusions of our findings on the relevance of MCDA to invasive animal countermeasure selection by land managers and other decision makers.

\section{Development of the MCDA Model}


The first step in developing a decision model is to contextualize and scope the decision one is attempting to model. The goal of selecting an eradication technique to remove wild pigs from a specific area was identified. The decision maker should develop a set of truths about the current state of the problem they are dealing with (i.e. land size considered, number of pigs). Our model does not consider the dynamics associated with things such as pig adaptations, changes in preferences and values, etc. This model should therefore be used iteratively and adapted over the course of time as the problem changes. An appropriate time frame should be chosen to periodically return back to these set of truths and re-assess them.

The next step, following a value-focused thinking approached identified by Keeney (2009), is to identify relevant criteria and sub-criteria consistent with the decision objectives by which the countermeasures will be assessed. When determining which countermeasure is their best available option, decision makers have to consider many different criteria, including feasibility, cost, environmental concerns, and stakeholder interests (Campbell and Long 2009). These criteria represent trade-offs which cannot be made based upon a single metric (such as number of pigs killed) - numerous heterogeneous and dissimilar considerations must be factored into the decision process. These trade-offs are often difficult to compare without a formal methodology. After these criteria are identified, they must be weighted by the decision maker or stakeholders to represent their relative importance. Each criterion is then scored for each countermeasure in terms of how well that particular criterion performs, and these weights and scores are typically combined in an additive model to reach an aggregated score for each countermeasure representing the extent to which they meet the decision making objectives. These scores may then be compared to one another, and sensitivity analysis conducted to gain 
insight into the relative strengths and weaknesses of each countermeasure. This methodology is the general foundation for performing a multi-criteria decision analysis (MCDA).

With the goal of developing a tool for decision makers (i.e. land managers, natural resource managers), we propose the following application for decision analytic methods for the management of invasive feral pigs.

We gathered a list of criteria that the decision maker may consider when making their choice: land traversing, efficacy, training needed, total financial cost, non-target species impact, environmental impact, and public acceptance. These criteria are based on an extensive literature review and various discussions with wild pig experts. Explicit definitions of each of these criteria are available in Table 3. 'Land Traversing' refers to how easily a person can move across the terrain on site. 'Training Needed' refers to the amount of new training that one might need in order to apply this countermeasure. In our model, it has been assumed that the decision maker has never applied a countermeasure and therefore would need to learn how to implement the technique. A reassessment or readjustment of scores would allow this assumption to be relaxed. 'Financial Cost' refers to the economic cost of implementing an adaptive management program. It should be noted that we make the assumption that there are no resources currently available for implementation of any of the countermeasures. This assumption is extremely important because if, for example, a decision maker already has the materials and man-power on hand to perform a specific eradication technique they will not incur the financial costs suggested by our model. 'Non-Target Species Impact' refers to the potential for adversely impacting other species that may be present in the area. For example, if using dogs for hunting and they accidentally attack a white tailed deer instead of a pig this would be considered an adverse non-target species impact. 'Environmental Impact' includes downstream life cycle impacts, such as air and soil pollution, 
resource depletion, land use changes, etc. Lastly we have included 'Social Acceptance' as a criterion for consideration. Social Acceptance refers to how others in the local or regional community may perceive the countermeasures taken. For example if the local community may become angry about helicopters flying low near them, one would definitely want to consider this when making our decision. It is a subjective matter to determine how humane a countermeasure is, and so predicting how much various stakeholders may find the potential countermeasures can be a daunting task. Understanding values of these stakeholders at an early stage in the decision process will allow for improved prediction of concerns regarding humaneness.

\begin{tabular}{|c|l|l|}
\hline Criteria & \multicolumn{1}{|c|}{ Sub-Criteria } & \multicolumn{1}{c|}{ Guiding Question } \\
\hline Feasibility & Land Traversing & $\begin{array}{l}\text { How much does being able to move across the land } \\
\text { effect this countermeasure? }\end{array}$ \\
\cline { 2 - 3 } & Training Needed & $\begin{array}{l}\text { How much on-site training is needed to implement } \\
\text { this plan? (assume outsourcing is not an option) }\end{array}$ \\
\cline { 2 - 3 } & Efficacy & $\begin{array}{l}\text { How effective is the countermeasure in eradicating } \\
\text { pigs? }\end{array}$ \\
\hline Environmental & Non-target Species Impact & $\begin{array}{l}\text { How much damage can potentially be done to non- } \\
\text { target species? (i.e. accidental killing of deer, bear) }\end{array}$ \\
\cline { 2 - 3 } & Environmental Impact & $\begin{array}{l}\text { How much environmental damage will this } \\
\text { countermeasure cause? (i.e. air pollution, energy } \\
\text { consumption) }\end{array}$ \\
\hline Focial & Social Acceptance & $\begin{array}{l}\text { How socially-accepted is the countermeasure? Will the } \\
\text { public find it to be humane? }\end{array}$ \\
\hline Financial & Financial Cost & $\begin{array}{l}\text { How much will the program cost to implement? } \\
\text { Assume no resources are currently held on-site. } \\
\text { Consider training, materials needed, contracts needed, } \\
\text { as well as management and oversight costs. }\end{array}$ \\
\hline
\end{tabular}

Table 3. Definitions of Decision Criteria

In order to build a value hierarchy which seeks to organize goals and corresponding criteria in a way that facilitates scoring and weighting, these criteria are grouped into four distinct categories: Feasibility, Environmental, Financial, and Social. This is important because it allows for the logical structuring values and associated tradeoffs (Belton \& Stewart, 2001). Feasibility covers criteria that are concerned with how realistic the countermeasure will be to 
implement (Land Traversing, Efficacy, and Training Needed). Measuring the difficulty of land traversing is very important because it can slow down the eradication drastically. Efficacy of an eradication technique (e.g. financial and temporal efficiency) is measured based on the pig density and land type (open or covered). Environmental criteria covers Non-Target Species Impact and overall Environmental Impact (which covers downstream, life cycle impacts). Financial only contains the Financial Cost associated with implementing the countermeasure, however this could easily be extended to include both long-term costs as well as short-term costs. Likewise, the social category only considers Social Acceptance from the public, but could easily be extended to include a more granular breakdown of social aspects (i.e. national perception, localized perception).

Next, a list of potential eradication techniques was developed: trapping, snaring, ground shooting (no dogs), ground shooting (with dogs), aerial shooting, and sport hunting (Table 4). We have chosen a subset of techniques that are widely accepted among land managers in order to provide a generalized tool.

\begin{tabular}{|l|l|}
\hline Countermeasure & Definition \\
\hline Trapping & $\begin{array}{l}\text { Involves setting up an enclosed space with bait inside in order to capture the pig(s) } \\
\text { alive. Traps can be made for one pig or multiple. }\end{array}$ \\
\hline Snaring & $\begin{array}{l}\text { A hooking mechanism that is designed to tighten as the pig runs through it. Snares } \\
\text { capture one pig at a time. }\end{array}$ \\
\hline $\begin{array}{l}\text { Ground } \\
\text { Shooting (No } \\
\text { Dogs) }\end{array}$ & $\begin{array}{l}\text { Using trained shooters to shoot the pigs, generally with rifles. This involves walking } \\
\text { through the woods on foot. }\end{array}$ \\
\hline Aerial Shooting & Using trained sharpshooters to shoot the pigs out of helicopters. \\
\hline Hunt with Dogs & $\begin{array}{l}\text { Using trained dogs to sniff out the wild pigs in certain areas in order to more easily } \\
\text { locate the pigs. Shooters follow the dogs and shoot the pigs when the dogs have } \\
\text { identified them. }\end{array}$ \\
\hline Sport Hunting & $\begin{array}{l}\text { Allowing anyone to shoot the pigs, assuming they are following all local and federal } \\
\text { laws. }\end{array}$ \\
\hline
\end{tabular}

Table 4. Definitions of Eradication Techniques 
In the next step of MCDA, one must identify a measurement scale in which to quantify the performance of a countermeasure against each criterion. In general, when quantitative measurements are available, they are strongly preferred over qualitative measures. However, it is often the case that qualitative or semi-quantitative measurements must be used. In this paper, semi-quantitative measurements are used and described in the Appendix. These measurement scales are used to create value functions, which transform the performance scores in terms of the measured units to a dimensionless quantity, often on a 0-100 scale. Here we use a linear value function, with a respondent score of 1 representing the most desirable performance (set at a value of 100) and 6 as the least desirable performance (set at a value of 0 ). This dimensionless value score $\left(\mathrm{S}_{\mathrm{ij}}\right)$ is multiplied by an assigned weight $\left(\mathrm{W}_{\mathrm{j}}\right)$ which represents the relative importance of criterion $\mathrm{j}$. There are a number of specific weigh-elicitation methods used in the field of Decision Analysis, including rank-based methods, point-allocation methods, swing weighting, and pairwise comparisons (Stillwell et al., 1981; Jia et al., 1998; Bottomley \& Doyle, 2001; Belton \& Stewart, 2002). In order to develop an aggregated value score (V) for each countermeasure (i), a weighted summation is taken using weights $\left(\mathrm{W}_{\mathrm{j}}\right)$ across all of the criteria $(\mathrm{j})$ of the criteria scores $\left(S_{i j}\right)$ for each countermeasure. Mathematically, the value of a countermeasure (i) is defined as:

$$
V_{i}=\sum_{j=1}^{7} W_{j} S_{i j}
$$

The results are then output to the user on a results page so that the user is able to compare the countermeasures against one another. A stacked bar chart also shows the user a transparent explanation of where the contributions to the value for that countermeasure originate. This enables the user to identify strengths and weaknesses of each countermeasure to ensure that the decision maker can see not just which countermeasure provides the best solution, but more 
importantly where the advantages and disadvantages lie. This ultimately leads to a better understanding of the decision space and facilitates a more informed choice.

\section{Scoring Elicitation via Expert Surveys}

Due to the lack of available useful data, we developed a survey and asked wild pig experts to provide their best professional judgment. Wild pig experts were challenging to find, however we were able to receive responses from seven ranging across the United States affected areas. In our expert survey $(\mathrm{N}=7)$, we obtain the performance scores by asking the experts to rate the countermeasures for each criteria on a scale from 1-6, where, in general, 6 represents exceptional performance on that attribute and 1 represents a poor performance specifically worded to be relevant to that attribute (See Appendix for more detail on the measurement scales used). We also surveyed the experts to rate sub-criteria for the Feasibility and Environmental categories. Sub-criteria are explicitly rated against each other within their parent criteria (i.e. Feasibility sub-criteria are not rated against Environmental sub-criteria) because, in general, people are unable to make valid comparisons against sub-criteria from other parent criteria (Belton and Stewart, 2002).

There was one caveat to eliciting these scores: the sub-criterion Efficacy (under the Feasibility criterion) required an extra calculation so that efficiency of each countermeasure could be incorporated under different pig population densities as well as land cover. Pig population densities are split into 'high' and 'low', where high represents greater than or equal to one pig per 25 acres and low represents less than a pig per 25 acres. This value was based on prior discussions with pig experts. Next we ask the user to rate land cover as 'open' or 'covered', where open represents an open field and covered represents forested land. Experts rated the 
efficacy of each countermeasure under each pig population density/land cover combination on the same scale used for rating the criteria. This allows the tool to dynamically pull in a new set of efficacy weights depending on the site-specific scenario that the user inputs. For the criteria comparison scores and the efficacy table, averages of all the expert ratings were taken to determine the scores that would be used in the model. These values can be observed in Tables 5 and 6 below.

\begin{tabular}{|l|c|c|c|c|c|c|}
\cline { 2 - 6 } \multicolumn{1}{c|}{} & $\begin{array}{c}\text { Land } \\
\text { Traversing }\end{array}$ & $\begin{array}{c}\text { Training } \\
\text { Needed }\end{array}$ & $\begin{array}{c}\text { Financial } \\
\text { Costs }\end{array}$ & $\begin{array}{c}\text { Non-target } \\
\text { Species } \\
\text { Impact }\end{array}$ & $\begin{array}{c}\text { Environmental } \\
\text { Impact }\end{array}$ & $\begin{array}{c}\text { Social } \\
\text { Acceptance }\end{array}$ \\
\hline Trapping & 2.36 & 3.00 & 3.68 & 4.36 & 4.96 & 4.16 \\
\hline Snaring & 3.08 & 2.88 & 4.68 & 2.92 & 5.08 & 2.84 \\
\hline $\begin{array}{l}\text { Ground } \\
\text { shooting }\end{array}$ & 3.20 & 3.08 & 4.68 & 5.16 & 5.40 & 4.52 \\
\hline Aerial shooting & 4.16 & 1.64 & 1.12 & 5.52 & 5.16 & 3.68 \\
\hline Hunt with dogs & 2.60 & 3.04 & 3.60 & 4.00 & 4.84 & 2.88 \\
\hline Sport hunting & 3.00 & 4.56 & 5.64 & 4.08 & 5.08 & 4.16 \\
\hline
\end{tabular}

Table 5. Scores for countermeasures on all performance criteria, averaged across experts

A comparison of Table 5 with the strengths and weaknesses identified by Campbell \& Long (2009) (Table 1) confirms many of these relationships. For example, aerial shooting received only a 1.14 (out of 6 possible points) on Financial Costs where Campbell \& Long (2009) list "Very Expensive" on their table. Aerial shooting is also extremely effective at avoiding killing non-target species and received a high 5.49 (out of 6) in our survey.

\begin{tabular}{|l|c|c|c|c|}
\cline { 2 - 5 } \multicolumn{1}{c|}{} & $\begin{array}{c}\text { High Pig } \\
\text { Density }\end{array}$ & $\begin{array}{c}\text { Low Pig } \\
\text { Density }\end{array}$ & Open Land & $\begin{array}{c}\text { Covered } \\
\text { Land }\end{array}$ \\
\hline Trapping & 4.32 & 4.68 & 4.4 & 4.52 \\
\hline Snaring & 2.92 & 4.04 & 2.48 & 3.36 \\
\hline $\begin{array}{l}\text { Ground } \\
\text { shooting }\end{array}$ & 2.6 & 3.64 & 3.04 & 3.08 \\
\hline $\begin{array}{l}\text { Aerial } \\
\text { shooting }\end{array}$ & 3.4 & 3.16 & 4.64 & 2.48 \\
\hline $\begin{array}{l}\text { Hunt with } \\
\text { dogs }\end{array}$ & 2.84 & 2.96 & 2.96 & 3.08 \\
\hline $\begin{array}{l}\text { Sport } \\
\text { hunting }\end{array}$ & 2.72 & 3.32 & 2.92 & 2.92 \\
\hline
\end{tabular}


Table 6. Scores of countermeasure efficacy averaged across experts

Again, we can provide a simple sanity check by looking at various scores in Table 6 from the experts and comparing them with the real world. Snaring, for example received a low score (1.94) from the experts in terms of efficiency for snaring in high pig density populations and a 1.39 in open land. This aligns with the fact that snares catch only one animal at a time and can't be used without a secure anchor. Snaring received a much higher score (4.52) in low pig density populations as well as a 4.34 in forested lands for the same reasoning.

As with any survey, it is important to observe the reliability and accuracy of the data that was collected. This is especially true in data-scarce environments such as ours (i.e. $\mathrm{N}=7$ ), as survey bias and misinterpretation could confound results. Below we have computed the sample standard deviation for the scoring table.

\begin{tabular}{|l|c|c|c|c|c|c|}
\cline { 2 - 6 } \multicolumn{1}{c|}{} & $\begin{array}{c}\text { Land } \\
\text { Traversing }\end{array}$ & $\begin{array}{c}\text { Training } \\
\text { Needed }\end{array}$ & $\begin{array}{c}\text { Financial } \\
\text { Costs }\end{array}$ & $\begin{array}{c}\text { Non- } \\
\text { target } \\
\text { Species } \\
\text { Impact }\end{array}$ & $\begin{array}{c}\text { Environmental } \\
\text { Impact }\end{array}$ & $\begin{array}{c}\text { Social } \\
\text { Acceptance }\end{array}$ \\
\hline Trapping & 0.37 & 0.37 & 0.58 & 0.46 & 0.60 & 0.48 \\
\hline Snaring & 0.40 & 0.34 & 0.58 & 0.25 & 0.60 & 0.29 \\
\hline Ground shooting & 0.34 & 0.47 & 0.59 & 0.46 & 0.59 & 0.59 \\
\hline Aerial shooting & 0.61 & 0.10 & 0.10 & 0.59 & 0.53 & 0.37 \\
\hline Hunt with dogs & 0.45 & 0.41 & 0.48 & 0.44 & 0.59 & 0.36 \\
\hline Sport hunting & 0.42 & 0.50 & 0.66 & 0.37 & 0.60 & 0.58 \\
\hline
\end{tabular}

Table 7. Standard deviation of survey scores

From these results, we see relatively low standard deviations (average=.46). Assuming these survey data are normally distributed we observe a $95 \%$ confidence interval within \pm 1 point. In future studies, it would be ideal to collect a larger sample size in hopes of determining more accurate input scores. With the efficacy table we see very similar resulting variation among our survey respondents. 


\begin{tabular}{|l|c|c|c|c|}
\cline { 2 - 5 } \multicolumn{1}{c|}{} & $\begin{array}{c}\text { High Pig } \\
\text { Density }\end{array}$ & $\begin{array}{c}\text { Low Pig } \\
\text { Density }\end{array}$ & $\begin{array}{c}\text { Open } \\
\text { Land }\end{array}$ & $\begin{array}{c}\text { Covered } \\
\text { Land }\end{array}$ \\
\hline Trapping & 0.64 & 0.61 & 0.61 & 0.61 \\
\hline Snaring & 0.62 & 0.44 & 0.26 & 0.36 \\
\hline Ground shooting & 0.38 & 0.65 & 0.36 & 0.37 \\
\hline Aerial shooting & 0.46 & 0.38 & 0.58 & 0.47 \\
\hline Hunt with dogs & 0.46 & 0.31 & 0.44 & 0.44 \\
\hline Sport hunting & 0.37 & 0.65 & 0.43 & 0.40 \\
\hline
\end{tabular}

Table 8. Standard deviation of survey efficacy scores

Again, standard deviation scores are relatively low across all efficacy scores. It is important to note that in both tables variation is consistent $(\min =.10, \max =.66)$. This means that experts were consistent in their disagreements about the scores and therefore minimal survey bias was achieved.

\section{Case Study}

In order to demonstrate the efficacy of this concept, an Excel-based model was developed and a notional, but realistic, case study was performed. In this case study, a standard crop farmer faces a large pig population. This farmer is likely to have large open spaces on his land. He is likely to value a low-cost solution that can be implemented quickly with minimal training. He is not likely to have other non-target species on his land, while he probably does care somewhat about the impact on the environment. The locals in his area understand his need to rid his crops of the invasive pigs, so he doesn't value social acceptance as he already has approval from the community. From this set of values, estimates for the following inputs are shown in Table 7 , which are normalized as weights (using a rank-based weighting method, Jia et al. 1998) in the decision model. 


\begin{tabular}{|c|c|c|}
\hline Criteria & Rating & Normalized Score \\
\hline Feasibility & 5 & 0.33 \\
\hline Financial & 6 & 0.40 \\
\hline Environmental & 3 & 0.20 \\
\hline Social & 1 & 0.07 \\
\hline
\end{tabular}

\begin{tabular}{|c|c|c|c|}
\hline Category & Sub-Criteria & Rating & Normalized Score \\
\hline \multirow{3}{*}{ Feasibility } & Land Traversing & 4 & 0.27 \\
\cline { 2 - 4 } & Efficacy & 6 & 0.40 \\
\cline { 2 - 4 } & Training Needed & 5 & 0.33 \\
\hline \multirow{2}{*}{ Environmental } & Non-target Species Impact & 1 & 0.20 \\
\cline { 2 - 4 } & Environmental Impact & 4 & 0.80 \\
\hline
\end{tabular}

Table 9. Farmer case study weights

By selecting these values, as well as setting the Pig Density to "High" and Land Cover to "Open Land", the following results are obtained as scores for the various countermeasures (Figure 2).

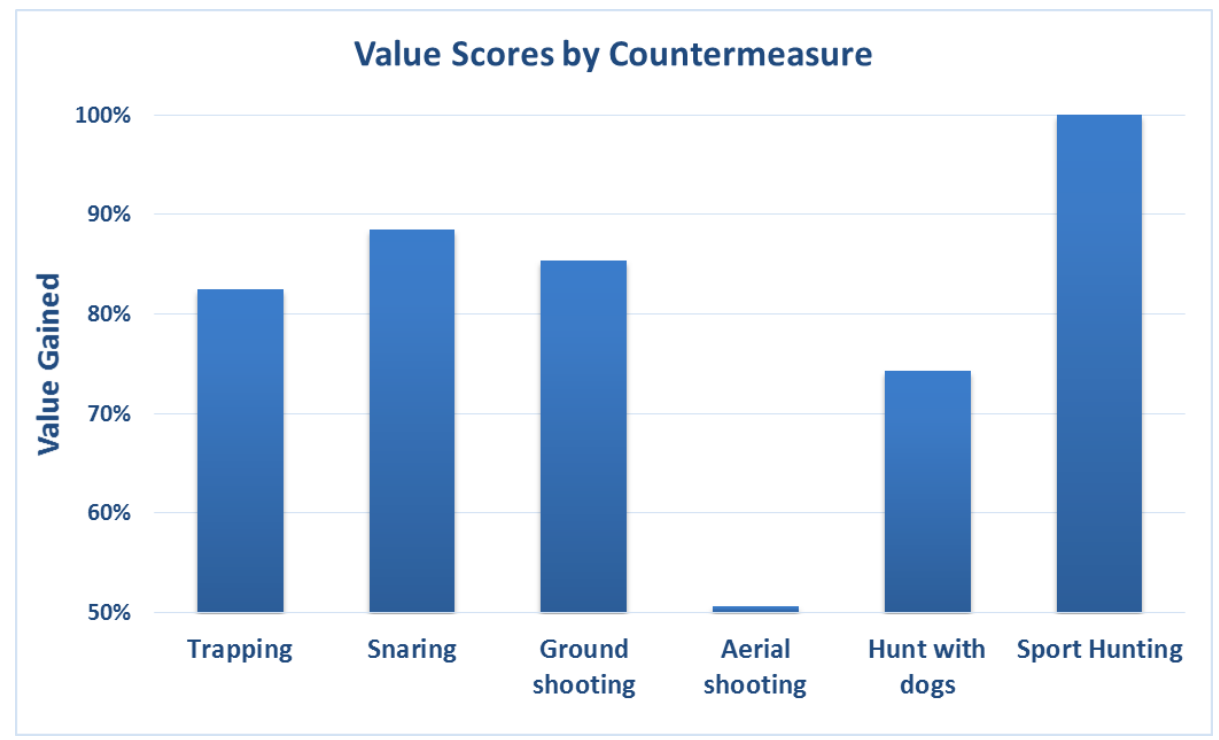

Figure 2. Resulting comparison of countermeasures under a case study scenario of a standard crop farmer who faces a large pig population

From these results, it appears that sport hunting is the best decision because it provides us with the most value. The next best option is snaring, which provides roughly $88 \%$ of the value gained by sport hunting, although snaring scores highly as well. The decision maker will 
inherently question why sport hunting will be the best decision. Figure 3 answers this question by allowing the user to thoroughly investigate how each of the criteria contribute to the various countermeasures.

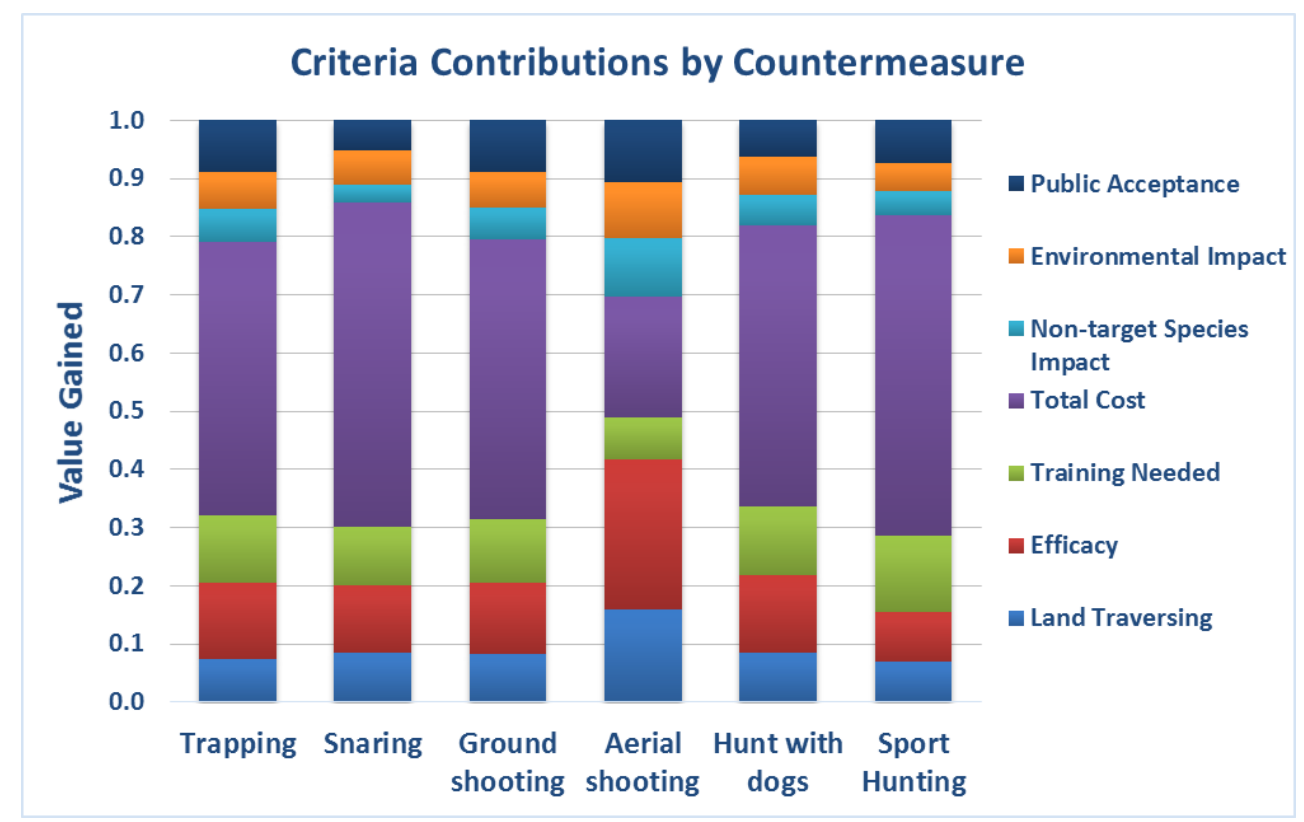

Figure 3. Contributions of each criterion to overall weighted value for each countermeasure.

Size of different colored bars represent the relative influence of that particular criterion to the overall value if that countermeasure. The criterion "Total Cost" dominates most of the criteria in this example. For example, roughly $55 \%$ of the value earned by sport hunting is coming from the "Total Cost" criteria. This makes sense, since the farmer was mostly concerned about cost and sport hunting is a relatively inexpensive countermeasure. Another interesting finding comes from the contributions being made by the "Public Acceptance" criteria across all of the countermeasures. By placing a rating of 1 on that criteria, the farmer did not care about what the community perceived of his eradication campaign. This aligns with the model output in that the contributions from "Public Acceptance" are small across all of the countermeasures. In summary, this tool not only allows a user to compare different eradication techniques, but allows complete transparency for understanding why certain countermeasures outperform others. 


\section{Discussion and Conclusions}

Wild pigs are a highly intelligent and adaptive species that have grown to be highly cautious and extremely wary of possible traps. Their adaptive nature, as well as environmental changes, shifts in stakeholder priorities, or policy changes can result in the originally chosen countermeasure becoming less effective, or another countermeasure may become available which is believed to be more effective (Katahira et al. 1993). Adaptive management allows managers to react to these changes by leveraging new information in the face of uncertainty and changing conditions by modifying project activities that more effectively achieve project goals (Holling 1978; Walters 1986). Learning is a natural objective of adaptive management: the more we learn, the more we can adapt our strategy to improve management success and the ability to cope with future changes (Johnson 1999). MCDA can serve as a platform in which to employ adaptive management. Used in conjunction with MCDA, adaptive management can iteratively assess the best eradication or population reduction countermeasure and adaptively revise strategies over time, striking the difficult balance between the reduction of uncertainty through additional monitoring and the costs of doing so (Collier et al., 2011). Figure 4 shows how adaptive management can enhance an eradication plan. The adaptive management process employs an active monitoring program to gauge the relative success of the various strategies employed. This feedback loop allows for managers to acquire new information about the presence or absence of wild pigs, which may ultimately cause the re-rating of countermeasures, adjustment of goals, or changes in criteria weights. This process encourages and emphasizes learning, changing methods, and adjusting strategies (Ferguson, et al., 2006). 


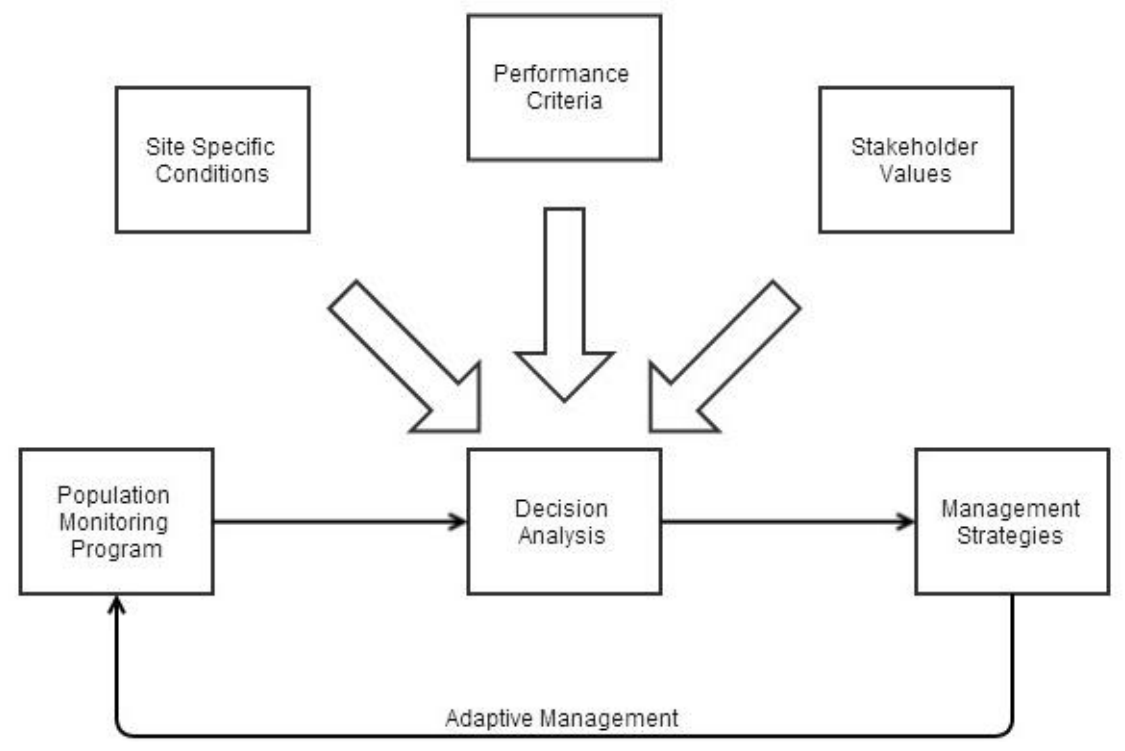

Figure 4 Continuous adaptive management loop.

Given the potentially damaging consequences posed by wild pigs and historically poor success rates in eradicating them, there is a need to move away from the status quo. Effective wild pig removal programs will require thoughtful planning, assessment of tradeoffs between multiple performance criteria, and execution of adaptive management strategies. Practitioners must be able to make better decisions than the wild pigs we are trying to control - decision analytic tools ensure that we can efficiently overcome these invasive pests before they adapt and outmaneuver us. This tool is one simple example of how decision analytics can aid the effort in combatting wild pigs. These tools can be easily adapted and extended for more complex situations at a broader or narrower scope. They provide a standardized framework which informs decision makers about the tradeoffs associated with such complex problems. This ultimately leads to better, more effective campaigns against invasive species. 


\section{Acknowledgements:}

This work was funded by the DoD Legacy Natural Resource Management Program, Project \#15-780 (Invasive Wild Pigs - Best Practices and Decision Support Tools). Permission was granted by the USACE Chief of Engineers to publish this material. The views and opinions expressed in this paper are those of the individual authors and not those of the US Army, or other sponsor organizations.

\section{References:}

Barrett, R.H., B. L. Goatcher, P. J. Gogan, E. L. Fitzhugh. 1988. Removing feral pigs from Annadel State Park. Transactions of the Western Section of the Wildlife Society 24:4753.

Baubet, E., S. Brandt, J. Vassant, J.-P. Gendner, F. Klein. 2004. Can wild boar be surveyed using GPS? Memoirs of National Institute on Polar Research 58: 188-195.

Belton V., T. Stewart. 2002. Multiple criteria decision analysis: an integrated approach. Kluwer Academic Publishers, Boston, Massachusetts.

Benke, K. K., J. L. Steel, J. E. Weiss. 2010. Risk assessment models for invasive species: uncertainty in rankings from multi-criteria analysis. Biological Invasions 13: 239-253.

Bomford, M., P. O’Brien. 1995. Eradication or control for vertebrate pests? Wildlife Society Bulletin 23: 249-255.

Bottomley, P.A., J.R. Doyle. 2001. A comparison of three weight elicitation methods: good, better, and best. Omega 29: 553-560

Campbell, T. A., D. B. Long. 2009. Feral swine damage and damage management in forested ecosystems. Forest Ecology and Management 257: 2319-2326. 
Choquenot, D., J. McIlroy, T. Korn. 1996. Managing vertebrate pests: feral pigs. Bureau of Resource Sciences, Australian Government Publishing Service, Canberra, ACT, Australia.

Choquenot, D., J. Hone, G. Saunders. 1999. Using aspects of predator-prey theory to evaluate helicopter shooting for feral pig control. Wildlife Research 26: 251-261.

Clemen, R.T. 1996. Making Hard Decisions: An Introduction to Decision Analysis, 2nd Ed. Boston: Duxbury Press.

Collier, Z. A., J. T. Vogel, S. G. Zemba, E. A. Ferguson, I. Linkov. 2011. Management tools for managing vapor intrusion. Environmental Science \& Technology 45: 8611-8612.

Converse, S. J., C. T. Moore, M. J. Folk, M. C. Runge. 2012. A Matter of tradeoffs: reintroduction as a multiple objective decision. The Journal of Wildlife Management. DOI: 10.1002/jwmg.472.

Cook, D., W. Proctor. 2007. Assessing the threat of exotic plant pests. Ecological Economics 63: $594-604$.

Diaz, J. H. 2007. Chagas disease in the United States: a cause for concern in Louisiana? The Journal of the Louisiana State Medical Society 159: 21-23, 25-29.

Davidson, W. R., and V. R. Nettles. 1997. Field manual of wildlife diseases in the southeastern United States. Southeastern Cooperative Wildlife Disease Study. University of Georgia. Athens, GA, USA

Elsey, R. M., E. C. Mouton Jr., \& N. Kinler. Effects of Feral Swine (Sus scrofa) on Alligator (Alligator mississippiensis) Nests in Louisiana. Southeastern Naturalist, 11, 205-218. 
Engeman, R. M., H. T. Smith, S. A. Shwiff, B. Constantin, J. Woolard, M. Nelson, D. Griffin. 2003. Prevalence and economic value of feral swine damage to native habitat in three Florida state parks. Environmental Conservation 30: 319-324.

Engeman, R. M., J. Woolard, H. T. Smith, J. Bourassa, B. U. Constantin, and D. Griffin. 2007a. An extraordinary patch of feral hog damage in Florida before and after initiating hog removal. Human-Wildlife Conflicts 1(2): 271-275.

Engeman, R. M., B. U. Constantin, S. A. Schwiff, H. T. Smith, J. Woolard, J. Allen, J. Dunlap. 2007b. Adaptive and economic management methods for feral hog control in Florida. Human-Wildlife Conflicts 1(2):178-185.

Executive Order 13112 (1999) Invasive Species. http://www.gsa.gov/portal/content/101587

Ferguson, E., Linkov, I., Satterstrom, F., Kiker, G., Bathcelor, C., \& Bridges, T. 2006. From comparative risk assessment to multi-criteria decision analysis and adaptive management: Recent developments and applications. Environment International, 32(8): 1072-1093.

Forrester, D. J. 1991. Parasites and diseases of wild mammals in Florida. University of Florida Press. Gainesville, FL, USA.

Gregory, R., G. Long. 2009. Using structured decision making to help implement a precautionary approach to endangered species management. Risk Analysis 29: 518-532.

Holling, C. S. 1978. Adaptive environmental assessment and management. John Wiley and Sons, New York, New York.

Howard, R.A. 1988. Decision analysis: Practice and promise, Management Science 34(6): 679695. 
Howard, R.A. 2007. The foundations of decision analysis revisited, Chapter 2 in Advances in decision analysis, ed. W. Edwards, R.F. Miles, and D. von Winterfeldt, 621. Cambridge, UK: Cambridge University Press.

Huang, I. B., Keisler, J., \& Linkov, I. 2011. Multi-criteria decision analysis in environmental sciences: ten years of applications and trends. Science of the total environment, 409(19): 3578-3594.

Izac, A.-M. N., P. O'Brien. 1991. Conflict, uncertainty and risk in feral pig management Australian approach. Journal of Environmental Management 32: 1-18.

Jia, J., Fischer, G.W., Dyer, J.S. 1998. Attribute Weighting Methods and Decision Quality in the Presence of Response Error: A Simulation Study. Journal of Behavioral Decision Making, Volume 11, Issue 2, pages 85-105

Johnson, B. L. 1999. The role of adaptive management as an operational approach for resource management agencies. Conservation Ecology 3(2): 8.

Kaller, M. D., J. D. Hudson III, E. C. Achberger, W. E. Kelso. 2007. Feral hog research in western Louisiana: expanding populations and unforeseen consequences. HumanWildlife Interactions 1: 168- 177.

Kangas J, Kangas A, Leskinen P, Pykalainen J (2001) MCDM methods in strategic planning of forestry on state-owned lands in Finland: applications and experiences. Journal of MultiCriteria Decision Analysis 10:257-271.

Katahira, L., Finnegan, P., \& Stone, C. (1993). Eradicating Feral Pigs in Montane Mesic Habitat at Hawaii Volcanoes National Park. Wildlife Society Bulletin, 21(3), 269-274.

Keeney RL. 2009. Value-Focused Thinking: A Path to Creative Decision Making. Harvard University Press: Cambridge. 
Keeney, R. and Raiffa H. (1976): Decisions with multiple objectives; preferences and value trade-offs. New York: J. Wiley and Sons.

Linkov, I., E. Mober. 2011. Multi-criteria decision analysis: environmental applications and case studies. CRC Press, Boca Raton, Florida.

Liu, S., W. Proctor, D. Cook. 2010. Using an integrated fuzzy set and deliberative multi-criteria evaluation approach to facilitate decision-making in invasive species management. Ecological Economics 69: 2374-2382.

Lohr, C. A., C. A. Lepczyk, and L. J. Cox. 2014. Identifying people's most preferred management technique for feral cats in Hawaii. Human-Wildlife Interactions 8(1): 56-66.

Løken E. 2007. Use of Multicriteria Decision Analysis Methods for Energy Planning Problems, Renewable and Sustainable Energy Reviews 11: 1584-1595.

Maguire, L.A. 2004. What can decision analysis do for invasive species management? Risk Analysis 24: 859-868.

McCann, B.E., D. K. Garcelon. 2008. Eradication of feral pigs from Pinnacles National Monument. The Journal of Wildlife Management 72: 1287-1295.

Mersinger, R. C., N. J. Silvy. 2007. Range size, habitat use, and dial activity of feral hogs on reclaimed surface-mined lands in east Texas. Human-Wildlife Interactions 1: 161-167.

Pfeiffer, J. M., R. A. Voeks. 2008. Biological invasions and biocultural diversity: linking ecological and cultural systems. Environmental Conservation 35: 281-294.

Pimental, D. 2007. Environmental and Economic Costs of Vertebrate Species Invasions into the Unites States. Managing Vertebrate Invasive Species: Proceedings of an International Symposium (G. W. Witmer, W.C. Pitt, K. A. Fagerstone, Eds). USDA/APHIS/WS, National Wildlife Research Center, Fort Collins, CO. 2007. 
Raiffa, H. (1968) Decision Analysis. Reading, MA: Addison-Wesley.

Ramsey, D. S. L., J. Parkes, S. A. Morrison. 2008. Quantifying eradication success: the removal of feral pigs from Santa Cruz Island, California. Conservation Biology 23: 449-459.

Saaty T. (1980): The Analytic Hierarchy Process, McGraw Hill, New York.

Samuel, W. M., M. J. Pybus, and A. A. Kocan, editors. 2001. Parasitic diseases of wild mammals. Iowa State University Press, Ames, USA.

Southeastern Cooperative Wildlife Disease Study (2016). Historic Wildlife Range Maps. University of Georgia, Athens. http://vet.uga.edu/scwds/range-maps

Stillwell, W. G., Seaver, D.A., Edwards, W. 1981. A Comparison of Weight Approximation Techniques in Multi-attribute Utility Decision Making. Organizational Behavior and Human Performance, 28(1): 62-77.

USDA. 2013. 2012 Feral Swine Management Report. United States Department of Agriculture Animal Plant Health Inspection Service Wildlife Services, Washington, DC.

USDA. 2014. USDA Announces $\$ 20$ Million Effort to Reduce Damage Caused by Feral Swine. News Release, April 2, 2014.

Walters, C. J. 1986. Adaptive management of renewable resources. Blackburn Press, Caldwell, New Jersey.

Wilcox, J., E. Aschehoug, C. Scott, D. Van Vuren. 2004. A test of the judas technique as a method for eradicating feral pigs. Transactions of the Western Section of the Wildlife Society 40: 120-126.

Williams, E. S., and I. K. Barker, editors. 2001. Infectious diseases of wild mammals. Iowa State University Press, Ames, USA. 
Wood, G. W., \& Barrett, R. H. (1979). Status of wild pigs in the United States. Wildlife Society Bulletin, 237-246.

Yoe C (2002) Trade-Off Analysis Planning and Procedures Guidebook. Prepared for Institute for Water Resources, US Army Corps of Engineers, April 2002

Zwickel, F. C. 1971. Use of dogs in wildlife management. The Wildlife Society, Washington, D.C. 
Appendix: Subject Matter Expert Survey

Feral Pig Decision Analysis Survey

Deciding which technique to use can be extremely complex due to the various contributing factors in a broad range of domains such as financial, environmental, and social. The purpose of this project is to assist in the development of a decision tool which will assist land managers in making decisions on how to best eradicate wild pig populations. The tool is based upon multi criteria decision analysis, which allows us to incorporate elements from each of the previously mentioned domains.

We have broken the decision down into 6 potential options ("Eradication Techniques") and 7 contributing factors (“Technique Attributes"). We would like to request your expert opinion to better understand how these techniques are influenced by different attributes. Please see below for brief descriptions of the eradication techniques as well as the attributes we would like to assess. Finally, there is a time-efficiency table that looks at better characterizing how well the different eradication techniques perform under different density's of pig populations and terrains. If you have any questions feel free to reach out:

E-Mail: Matthew.C.Brondum@usace.army.mil

Phone: 601-634-3636

\section{Description of Eradication Techniques}

Trapping: involves placing bait inside a fenced in area which automatically shuts once the pig(s) enter.

Snaring: involves setting up snares on anchor points in order to catch wild pigs.

Ground Shooting: involves using trained shooters to search the land for pigs and shoot them with rifles.

Aerial Shooting: involves having a sharpshooter shoot the pigs from a helicopter. 
Hunt with Dogs: involves using trained hunting dogs to search the land for pigs.

Sport Hunting: involves allowing sport hunters to hunt wild pigs on land.

Note: when assessing these eradication techniques, assume no prior knowledge or materials are to be used.

\section{Description of Technique Attributes}

Land Traversing: How much does being able to move across the land effect this countermeasure?

1: being able to move across the land highly impacts the ability to use the countermeasure 6: being able to move across the land easily doesn't affect the countermeasure at all

Training Needed: How much on-site training is needed to implement this plan? (assume we are NOT outsourcing anything)

1: countermeasure requires intensive training of many men

6: countermeasure requires no training at all

Financial Costs: How much will the program cost to implement? Assume no resources are currently held on-site. Don't forget to consider training, materials needed, contracts needed.

1: the program will be extremely expensive compared to the organizations budget

6: the program will not cost anything at all compared to the organizations budget

Non-target Species Impact: How much damage can potentially be done to non-target species (i.e. accidental killing of deer, bear, rabbits)?

1: $100 \%$ chance of mistakenly hurt other animals

6: $0 \%$ chance of mistakenly hurt other animals

Environmental Impact: How much environmental damage will this countermeasure cause? (i.e. air pollution, energy consumption)

1: $100 \%$ chance of serious environmental impact

6: $0 \%$ chance of any environmental impact at all

Social Acceptance: How socially-accepted is the countermeasure? Will the public find it to be humane?

1: public perception is that it is extremely inhumane to use this countermeasure (i.e. completely unethical)

6: public perception is that there is no reaction or publicity from using this technique

\section{Description of Time Efficiency Table}

Through this table, we are trying to better understand how effective the eradication techniques are under different pig densities and geographic spaces. 
High/Low Pig Density: Think of this in terms of how much time and money would need to be invested compared to the number of pigs per hectare. Generally speaking, would the technique be more efficient under high/low density?

Low Pig Density: 0-1 pigs/hectare

High Pig Density: 1+ pigs/hectare

1: Extremely inefficient

6: Extremely efficient

Open/Covered Land: Land type can greatly influence how effective a technique is. Generally speaking, would the technique be more efficient in open areas or forested areas?

Open Land: Less than $40 \%$ canopy cover

Covered Land: $40 \%$ or higher canopy cover

1: Extremely inefficient

6: Extremely efficient

\section{Name: \\ Organization:}

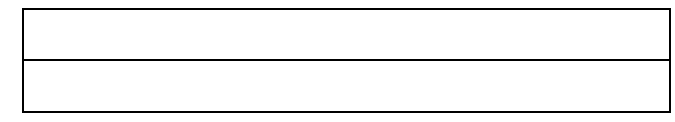

Instructions: This score sheet is designed to compare different countermeasures to wild pig eradication techniques. There are seven different attributes listed at the top of the chart. Countermeasures are listed along the left side. We would like to rate each countermeasure from 1 to 10 on its relative dependency/impact on the attributes listed. 1 signifies an "extremely bad" rating while 6 signifies extremely good rating.

For example: if you believe that aerial shooting is an extremely expensive countermeasure to implement, that cell should have a very low score (say 2).

\begin{tabular}{|c|c|c|c|c|c|c|c|}
\hline & & \multicolumn{6}{|c|}{ Attributes } \\
\hline & & $\begin{array}{c}\text { Land } \\
\text { Traversing }\end{array}$ & $\begin{array}{l}\text { Training } \\
\text { Needed }\end{array}$ & $\begin{array}{c}\text { Financial } \\
\text { Cost }\end{array}$ & $\begin{array}{c}\text { Non-target } \\
\text { Species } \\
\text { Impact }\end{array}$ & $\begin{array}{l}\text { Environmental } \\
\text { Impact }\end{array}$ & $\begin{array}{c}\text { Social } \\
\text { Acceptance }\end{array}$ \\
\hline \multirow{6}{*}{ 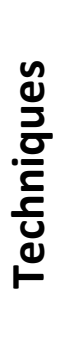 } & Trapping & & & & & & \\
\hline & Snaring & & & & & & \\
\hline & $\begin{array}{c}\text { Ground } \\
\text { shooting }\end{array}$ & & & & & & \\
\hline & Aerial shooting & & & & & & \\
\hline & Hunt with dogs & & & & & & \\
\hline & Sport hunting & & & & & & \\
\hline
\end{tabular}


Instructions: In the table below, we would like you to rate how efficient the different techniques are when there are a lot of pigs in the area or when there are only a few pigs in the area. 1 means inefficient, 6 means very efficient.

Comments can be seen explaining each efficiency category by hovering over it's cell in Row 19.

For example: if you believe that trapping is very effective in low pig density populations that cell should have a very high number (say 9).

Time Efficiency Table

\begin{tabular}{|c|c|c|c|c|}
\cline { 2 - 5 } \multicolumn{1}{c|}{} & $\begin{array}{c}\text { High Pig } \\
\text { Density }\end{array}$ & $\begin{array}{c}\text { Low Pig } \\
\text { Density }\end{array}$ & $\begin{array}{c}\text { Open } \\
\text { Land }\end{array}$ & $\begin{array}{c}\text { Covered } \\
\text { Land }\end{array}$ \\
\hline Trapping & & & & \\
\hline Snaring & & & & \\
\hline Ground shooting & & & & \\
\hline Aerial shooting & & & & \\
\hline Hunt with dogs & & & & \\
\hline Sport hunting & & & & \\
\hline
\end{tabular}




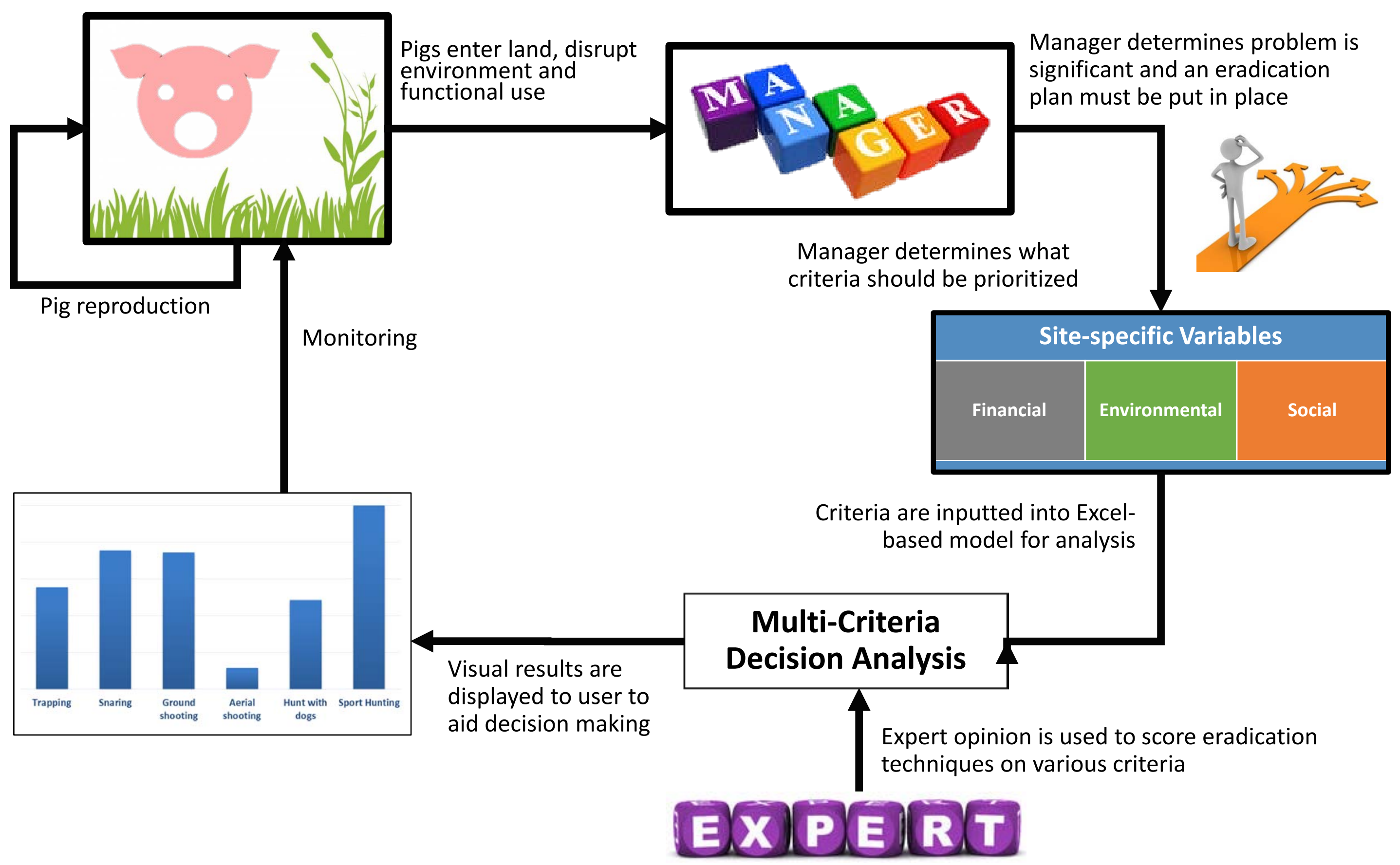

